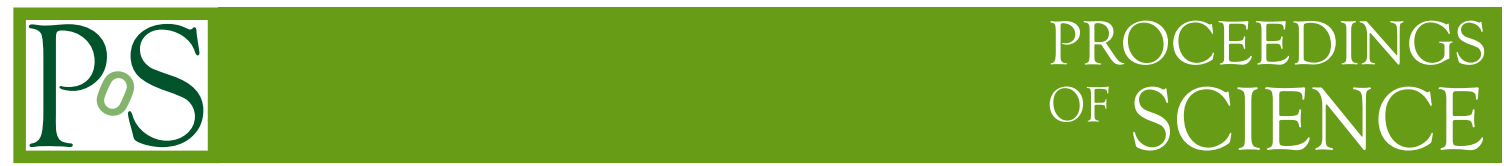

\title{
Kurt Gödel's theory of gravitation
}

\section{Eric Audureau*}

Centre d'Epistémologie et d'Ergologie Comparative

E-mail: eric.audureauduniv-amu.fr

Gödel's contribution to GR [1] have been criticized by several first rank physicists like Chandrasekhar, R.Ellis, S.Hawking, R.Penrose, J.Wheeler [2]. These criticisms (lack of physical meaning, violation of causality,...) contrast with Gödel own description of his work: "[It] relates to the pure theory of gravitation published in 1916 which, I believe, was left, not only by Einstein himself but also by the whole generation of contemporary physicists, in its state of a torso, physically, mathematically, and with respect to its application in cosmology." I will, in first place, explain why reccurent crticisms addressed to Gödel's exact solutions of Einstein's field equations are unjustified. In second place, I will illustrate in what sense Gödel's contributions to GR is what Einstein tried to do in 1917, namely a completion of the theory of gravitation.

\section{References}

[1] Kurt Gödel, Collected Works, Volumes I-V, ed. S. Feferman et al., Oxford University Press, 1996-2004.

[2] C.W. Misner, K.S.Thorne, J.A.Wheeler, Gravitation, W.H.Freeman \& Co, 1973.

Frontiers of Fundamental Physics 14 - FFP14,

15-18 July 2014

Aix Marseille University (AMU) Saint-Charles Campus, Marseille

\footnotetext{
${ }^{*}$ Speaker.
} 